violet. It forms a picrate m.p. $117 \cdot 5^{\circ}$ (found : C, $35.9 ; \mathrm{H}, 2 \cdot 8 ; \mathrm{N}, 24 \cdot 6 . \quad \mathrm{C}_{12} \mathrm{H}_{7} \mathrm{O}_{7} \mathrm{~N}_{7} \cdot 2 \mathrm{H}_{2} \mathrm{O}$ requires C, $36 \cdot 2 ; \mathrm{H}, 2 \cdot 8 ; \mathrm{N}, 24 \cdot 7$ per cent), and an oxalate which decomposes without melting above $128^{\circ}$ (found: $\mathrm{C}, 37 \cdot 5 ; \mathrm{H}, 3 \cdot 5$. $\mathrm{C}_{8} \mathrm{H}_{6} \mathrm{O}_{4} \mathrm{~N}_{4} \cdot 2 \mathrm{H}_{2} \mathrm{O}$ requires C, $37.2 ; \mathrm{H}, 3.9$ per cent).

Imperial Chemical Industries, Ltd.,

$$
\text { W. G. M. Jones }
$$

Research Laboratories,

Hexagon House, Manchester 9. Aug. 10.

${ }^{1}$ Ber., 39, 250 (1906).

\section{Chemical Assay of Streptomycin B (Mannosido - Streptomycin)}

MoRris $^{1}$ has recently described the use of a new reagent $(0.2$ per cent anthrone, a reduction product of anthroquinone, in 95 per cent sulphuric acid) for quantitative determination of carbohydrates. We have found that it can be used not only for distinguishing streptomycin $B$ (a mannoside) from streptomycin $A$, but also for estimating the amount of the former present in a mixture. The glucosamine moiety, present in both molecules, apparently does not react with the reagent. Results obtained are in accord with those calculated from biological and chemical assays, making the accepted assumption about the relative biological activities of the two streptomycins.

It is hoped to publish elsewhere details of the analytical procedure, with some typical results.

W. B. EMERY

Fermentation Division,

A. D. WALKER

Glaxo Laboratories, Ltd. Barnard Castle,

Co. Durham.

July 30.

${ }^{3}$ Morris, Science, 107, 254 (1948).

\section{Molecular Weight of Malt-Amylase}

IN an earlier investigation ${ }^{1}$, the molecular weight of $\alpha$-amylase from pig's pancreas ${ }^{2,3}$ was found to be 45,000 , as calculated from the values ${ }^{4} s_{20}=4.50 \mathrm{~S}$, $D=8.05 \times 10^{-7}$ c.G.S. and $V_{20}=0.70$. At this Institute a new method for the isolation of amylase from malt has been developed ${ }^{5}$. It was shown that by repeated purification of the albumin fraction from malt a preparation was obtained with high $\alpha$-amylase and $\beta$-amylase activity. Therefore it was assumed that the amylase activity of malt is localized in the albumin fraction. By ultracentrifugation of the albumin fraction, only one peak was obtained. It must be stated here that malt-amylase is more polydisperse than $\alpha$-amylase from pancreas.

A determination of the molecular weight was carried out on an amylase preparation with a saccharification activity ${ }^{6}$ of 45,000 and a dextrinizing activity ${ }^{7}$ of 57,400 , calculated for the dry substance. The determination was carried out in a buffer solution with a concentration of $0.2 M$ sodium chloride, $0.03 M$ primary sodium phosphate and $0.02 M$ secondary sodium phosphate, $p \mathrm{H} 7$.

Ultracentrifuge measurement. The accompanying sedimentation diagrams were obtained by centrifuging at 65,000 r.p.m.
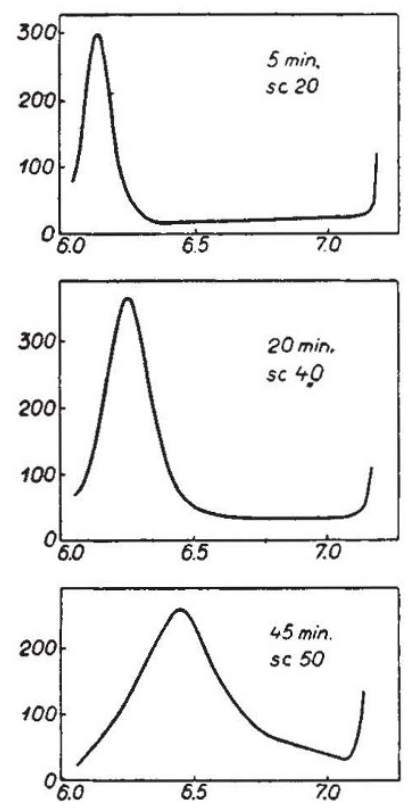

Sedimentation curves for malt-amylase. In Table 1 the sedimentation constants for different concentrations are shown

\begin{tabular}{cc}
\multicolumn{2}{c}{ Table 1 } \\
$\begin{array}{c}\text { Conc. of amylase } \\
\text { (per cent) }\end{array}$ & $\boldsymbol{8}_{\mathbf{2 0}} S$ \\
$0 \cdot 19$ & $4 \cdot 62$ \\
0.28 & $4 \cdot 44$ \\
0.31 & 4.96 \\
0.32 & 4.22 \\
0.41 & 4.76 \\
0.45 & 4.12 \\
0.75 & 4.69 \\
1.00 & 4.44 \\
1.05 & 4.39
\end{tabular}

The sedimentation constant is evidently independent of the concentration. An average value of the sedimentation constant is $s_{20}=4.52 \mathrm{~S}$.

Diffusion measurement. The determination of the diffusion constant was carried out in exactly the same way as for $\alpha$-amylase from pancreas ${ }^{1}$. The resulting values of the diffusion constant are shown in Table 2.

Diffusion time (sec.) Table 2

$\begin{array}{llllll}D_{m} & 6 \cdot 96 & 6 \cdot 70 & 6 \cdot 70 & 6 \cdot 59 & 6 \cdot 74 \\ D_{\Delta} & 6 \cdot 42 & 6 \cdot 20 & 6 \cdot 29 & 6 \cdot 36 & 6 \cdot 32\end{array}$

The agreement batween $D_{m}$ and $D_{A}$ is good. The average value of $D=6.53 \times 10^{-7}$ c.G.s. is used in the following. The value $V_{20}=0.69$ was kindly determined by Prof. C. Drucker. Using these values, the molecular weight of malt-amylase is 54,000 . Evidently this value is of the same order of magnitude as that for $\alpha$-amylase from pancreas. It is an interesting fact that the amylase activity is associated with molecules with about the same molecular weight in both the plant and animal kingdom.

Institute of Physical Chemistry, Carl-Erik Dantelsson

University of Uppsala. May 24.

${ }^{1}$ Danielsson, C.-E., Nature, 160, 899 (1947).

2 Meyer, K. H., Fischer, E. H., and Bernfeld, P., Experientia, 2, 362 (1946); Helv. Chim. Acta, 3), 64 (1947).

sischer, E. H., "La purification et l'isolement de l'a-amylase de pancréase".' Thèse No. 1094 (Genève, 1947).

- Svedberg, T., and Pedersen, K. 0., "The Ultracentrifuge" (Oxford, 1940).

${ }^{5}$ Danielsson, C.-E., and Sandegren, E., Acta Chem. Scand., 1, 917 (1947).

'Windisch, W., and Kolbach, P., Woch. Brau., 42, 139 (1925).

' Ehrnst, L. E., Yakish, G. J., and Olson, W., Cereal Chem., 16, 724 (1939). 